\title{
Inhibitory effect of sulindac on DMBA-induced hamster cheek pouch carcinogenesis and its derived cell line
}

\author{
EMI SEGAWA, SUSUMU HASHITANI, YUKIYO TOYOHARA, HIROMITSU KISHIMOTO, \\ KAZUMA NOGUCHI, KAZUKI TAKAOKA and MASAHIRO URADE \\ Department of Oral and Maxillofacial Surgery, Hyogo College of Medicine, \\ 1-1 Mukogawa-cho, Nishinomiya, Hyogo 663-8501, Japan
}

Received August 28, 2008; Accepted November 10, 2008

DOI: 10.3892/or_00000296

\begin{abstract}
In order to investigate the involvement of cyclooxygenase (COX)-2 in oral carcinogenesis and chemoprevention for it, we examined the COX-2 expression during dimethylbenzanthracene (DMBA)-induced hamster cheek pouch carcinogenesis and the inhibitory effect of sulindac, a non-steroidal anti-inflammatory drug (NSAID), on the carcinogenesis and its derived squamous carcinoma cell line HCPC-1. From the beginning of DMBA application, basal diet or diets containing sulindac 200 or 400 ppm were given to hamsters, and observation of tumor development and measurement of body weight were performed. Immunohistochemical analysis revealed that COX-2 expression was increased toward carcinogenesis from epithelial dysplasia to squamous cell carcinoma (SCC). All hamsters developed SCC, but the onset of carcinoma formation was significantly delayed up to 14.8 and 11.8 weeks in the $200 \mathrm{ppm}$, and $400 \mathrm{ppm}$ sulindac group, respectively, as compared to 8.7 weeks in the control group. In addition, tumor growth was retarded in the group of sulindac treatment, and mean survival time was 23.7 weeks in the control group and 36.3 and 33.8 weeks in the 200 and 400 ppm sulindac group, respectively. Body weight loss was not observed during the experimental period. Histologically, administration of sulindac inhibited angiogenesis in the tumor stroma. Treatment with sulindac sulfide, an active metabolite of sulindac, caused inhibition of cell growth, $\mathrm{PGE}_{2}$ production and VEGF production in $\mathrm{HCPC}-1$ cells in vitro. Expression of COX-2 protein in HCPC-1 cells was also decreased 2-fold by treatment with sulindac sulfide. It was thus indicated that inhibitory effects were partly due to inhibition of tumor angiogenesis by sulindac. These findings suggested the involvement of
\end{abstract}

Correspondence to: Professor Masahiro Urade, Department of Oral and Maxillofacial Surgery, Hyogo College of Medicine, 1-1 Mukogawa-cho, Nishinomiya, Hyogo 663-8501, Japan E-mail: uradem@hyo-med.ac.jp

Key words: cyclooxygenase-2, DMBA, hamster cheek pouch carcinogenesis, chemoprevention, sulindac
COX-2 in DMBA-induced hamster cheek pouch carcinogenesis and the chemopreventive potential of sulindac.

\section{Introduction}

Epidemiological and laboratory studies have indicated an inverse association between the risk of colorectal cancer and intake of non-steroidal anti-inflammatory drugs (NSAIDs) (1-4). Cyclooxygenases (COXs) have been postulated to be target molecules for NSAIDs and there are two known distinct isoforms in COXs, COX-1 and COX-2. COX-1 is constitutively expressed in most normal tissues and appears to be a housekeeping enzyme responsible for various physiological functions. On the other hand, COX-2 is an enzyme induced by mitogens, cytokines and growth factors of epithelial cells, and its pathophysiological role has been primarily connected to prostaglandin (PG) production in response to inflammation (5-8).

Sulindac, an NSAID, has been extensively studied for the pharmacological actions in both humans and animals. When administered orally, sulindac is reduced by gut flora to yield the active anti-inflammatory metabolite, sulindac sulfide, prior to absorption. Sulindac inhibits colorectal carcinogenesis in rodent models $(9,10)$ and causes regression of adenomas $(2,11)$ in patients with familial adenomatous polyposis coli. The mechanism by which this activity occurs is unclear, although some correlation has been found between sulindac treatment and reduced levels of prostaglandins in the human colorectal mucosa $(12,13)$. In relation to reduced prostaglandin levels, sulindac treatment was not found to be chemopreventive in all studies $(2,13)$. In addition, several studies indicate that sulindac and its metabolites have demonstrated chemoprotective effects through inhibition of angiogenesis $(14,15)$.

In this study, we examined the COX-2 expression during DMBA-induced hamster cheek pouch carcinogenesis and the inhibitory effect of sulindac on the carcinogenesis via inhibition of angiogenesis.

\section{Materials and methods}

Animals and carcinogen treatment. Eighteen male golden Syrian hamsters (5-week old) were purchased from Nihon Animal, Inc., Osaka, Japan and were treated by painting 
a buccal pouch 3 times a week for 13 weeks with a $0.5 \%$ solution of 9,10-dimethyl-1, 2-benzanthracene (DMBA, Wako Pure Chemical Industries, Ltd., Osaka, Japan) dissolved in acetone as described before (16). From the beginning of DMBA application, basal diet CE-2 (Japan Clea Co., Ltd., Tokyo, Japan) was given to hamsters and tumor development was observed. At intervals, tissue specimens applied with DMBA were taken for the histological and immunohistochemical examinations. Animals were sacrificed under ether anesthesia at the 10,13 and 16th week after the beginning of DMBA application.

Histological and immunohistochemical studies. Tissue specimens were fixed in $10 \%$ formalin, embedded in paraffin, and cut into $4-\mu \mathrm{m}$ thick sections according to conventional procedures. Histological examination was performed by hematoxylin and eosin (H\&E) stain. For immunohistochemical studies, a modification of the streptavidin-biotin-peroxidasecomplex (SABC) method (17) was employed by using rabbit polyclonal antibody against human COX-2 (IBL, Gunma, Japan). Non-immunized rabbit serum was used as negative control.

Administration of sulindac. From the beginning of DMBA application, hamsters were fed with basal diet or diets containing 200 and 400 ppm sulindac (Sigma-Aldrich Co., St. Louis, MO, USA). DMBA application was continued until the 13th week and observation of tumor development and measurement of body weight were performed. The relative tumor weights $(\mathrm{mg})$ were calculated using the formula $a^{2} \times b / 2$, where $a$ is the width in millimeters and $b$ is the length in millimeters, according to the method of Battelle Columbus Laboratories (18).

Cell line and cell culture. HCPC-1 (19) cells were isolated and established from 7,12-dimethylbenz $(\alpha)$ anthracenetransformed Syrian golden hamster cheek pouch squamous cell carcinoma and kindly provided by Professor G. Shklar (Harvard School of Dental Medicine, Boston, MA, USA). The culture was maintained in Dulbecco's modified Eagle's MEM (DMEM, Nissui Pharmaceutical Co., Tokyo, Japan) supplemented with $10 \%$ fetal bovine serum (HyClone Laboratories, Logan, UT, USA) and $4 \mathrm{mM}$ L-glutamine as growth medium at $37^{\circ} \mathrm{C}$ in a $5 \% \mathrm{CO}_{2}$ incubator.

Cell growth assay. Cells were plated at $2.5 \times 10^{4}$ cells $/ \mathrm{ml}$ in dishes and cultured in growth medium at $37^{\circ} \mathrm{C}$. Sulindac sulfide (Sigma-Aldrich) was dissolved in dimethylsulfoxide (DMSO) (Dojindo Laboratories, Kumamoto, Japan) before use and added to the culture medium at various concentrations after 24-h cultivation of cells. After further incubation at $37^{\circ} \mathrm{C}$ for $72 \mathrm{~h}$, cell growth was assessed by cell count using by trypan blue dye exclusion test by conventional microscopy. The $\mathrm{IC}_{30}$ concentration of sulindac sulfide was chosen as a less cytotoxic dose in a preliminary experiment.

Immunoassay for prostaglandin $E_{2}\left(P G E_{2}\right)$ and vascular endothelial growth factor (VEGF). HCPC-1 cells were plated at $5 \times 10^{4}$ cells in $3.5 \mathrm{ml}$ growth medium in $60-\mathrm{mm}$ tissue culture dish and grown at $37^{\circ} \mathrm{C}$ for $24 \mathrm{~h}$. The $\mathrm{IC}_{30}$ concen- tration of sulindac sulfide was added to the dishes and then cells were cultured for further $72 \mathrm{~h}$. The medium was discarded and $3.5 \mathrm{ml}$ of serum-free fresh medium was added to each dish, and then conditioned medium was collected after $15 \mathrm{~min}$ for $\mathrm{PGE}_{2}$ assay and after $24 \mathrm{~h}$ for VEGF assay. $\mathrm{PGE}_{2}$ assay was performed as described in a protocol of prostaglandin $\mathrm{E}_{2}$ EIA kit (Cayman Chemical, Ann Arbor, MI, USA) and VEGF assay was performed as described in a protocol of Quantikine Human VEGF Immunoassay (R\&D systems, McKinley, MN, USA).

Assay for microvessel density. Microvessels were detected by immunohistochemical staining for factor VIII/von Willebrand factor, a marker for vascular endothelial cells. After pretreatment with $0.25 \%$ trypsin for $10 \mathrm{~min}$, tissue sections were immunostained with a rabbit-factor VIII antibody $(1: 800$; Dako Corporation, Carpinteria, CA, USA) using the SABC method. Microvessel density (MVD) was determined by counting the number of vessels in high magnification field (x400) of the tumor stroma that contained the highest number of capillaries.

Western blot analysis. Cell lysates were subjected to Western blot as described previously (20). The primary antibodies used were goat polyclonal antibodies against COX-2 and actin (Santa Cruz Biotechnology, Santa Cruz, CA, USA). The secondary antibodies used were anti-goat IgG conjugated with alkaline phosphatase (Santa Cruz Biotechnology). Actin was used as an internal control.

Statistical Analysis. Statistical analysis was done by using the Student's t-test and Fisher's exact test. Differences were considered significant when the p-value was $<0.05$.

\section{Results}

Increased COX-2 expression during DMBA-induced hamster cheek pouch carcinogenesis. All hamsters were successfully treated 3 times a week with a $0.5 \%$ solution of DMBA dissolved in acetone and developed papillomatous tumors including precancerous or cancerous lesions. Approximately at the 5th week after DMBA application to buccal pouch, these hamsters showed hyperorthokeratosis of the buccal pouch squamous epithelium. From the 6th to the 9th week after DMBA application, papillomatous tumors developed in all hamsters. Histologically, these tumors resembled that of the squamous papilloma with or without mild epithelial dysplasia which was characterized by cellular atypia of the basal cells and some parabasal cells, mild nuclear pleomorphism and hyperchromatism. Additional topical application with DMBA induced a neoplastic transformation and formed carcinoma in situ or early invasive SCC. Finally, invasive SCC was produced by the 10th week after DMBA application and grew rapidly.

Immunohistochemical analysis revealed that COX-2 expression was increased toward carcinogenesis from epithelial dysplasia to SCC (Fig. 1). Normal squamous epithelium showed no COX-2 expression in the epithelial cells. In contrast, epithelial dysplasia showed positive reaction for COX-2 protein in basal cells and some parabasal cells. 

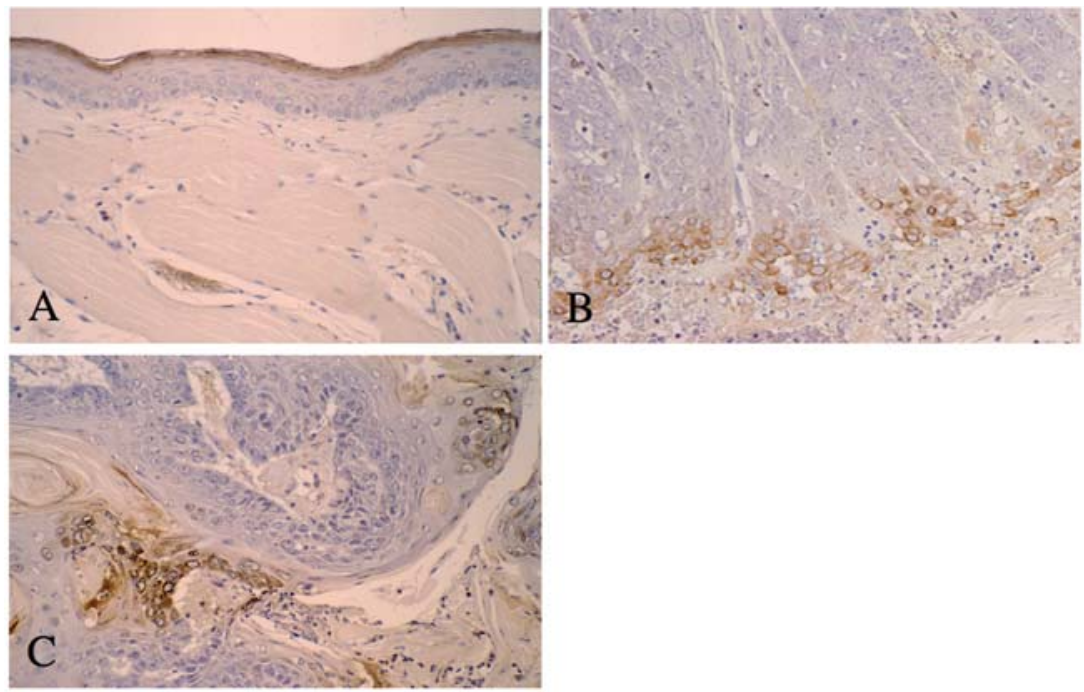

Figure 1. Photomicrographs of DMBA-induced SCC in hamster cheek pouch epithelium and immunohistochemical expression of COX-2 protein in the process of carcinogenesis. (A) Normal epithelium, (B) epithelial dysplasia, and (C) well-differentiated SCC in immunohistochemical staining for COX-2. (A-C) Original magnification, x200.

Table I. Chemopreventive activity of sulindac against DMBA-induced hamster cheek pouch carcinogenesis.

\begin{tabular}{|c|c|c|c|c|c|}
\hline & $\begin{array}{l}\text { Tumor } \\
\text { incidence } \\
(\%)\end{array}$ & $\begin{array}{l}\text { Onset of carcinoma } \\
\text { formation (weeks) }\end{array}$ & $\begin{array}{c}\text { Duration until relative } \\
\text { tumor weight reached } \\
500 \mathrm{mg} \text { from onset (weeks) }\end{array}$ & $\begin{array}{l}\text { Body weight } \\
\text { at 13th week (g) }\end{array}$ & $\begin{array}{c}\text { Mean survival } \\
\text { time (weeks) }\end{array}$ \\
\hline Control $(n=6)$ & $6 / 6(100)$ & $8.7 \pm 1.5$ & $5.2 \pm 1.2$ & $140.7 \pm 18.4$ & $23.7 \pm 2.5$ \\
\hline Sulindac 200 ppm $(n=6)$ & $6 / 6(100)$ & $14.8 \pm 0.75^{\mathrm{a}}$ & $6.5 \pm 3.3$ & $146.0 \pm 15.3$ & $36.3 \pm 10.6^{\mathrm{b}}$ \\
\hline Sulindac 400 ppm $(\mathrm{n}=6)$ & $6 / 6(100)$ & $11.8 \pm 0.75^{\mathrm{a}}$ & $6.8 \pm 1.8$ & $159.3 \pm 15.2$ & $33.8 \pm 5.1^{\mathrm{a}}$ \\
\hline
\end{tabular}

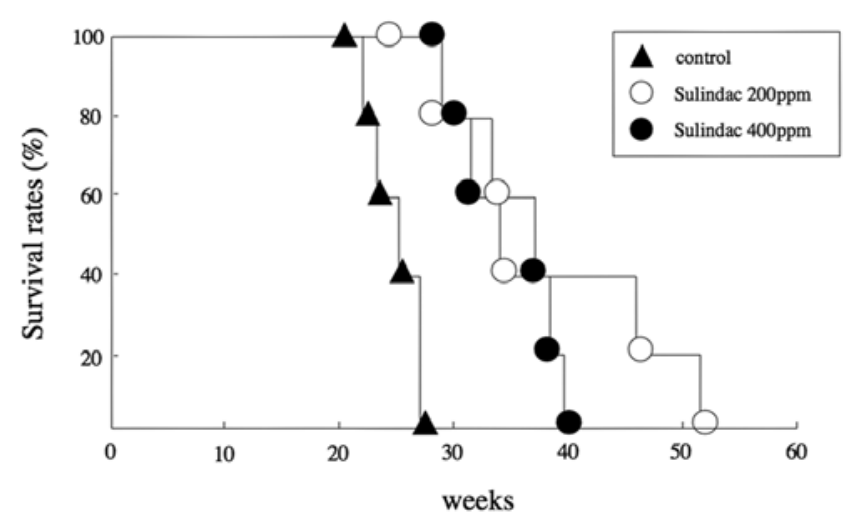

Figure 2. Survival time of hamsters with DMBA-induced cheek pouch SCC. ム, basal diet; o, diets containing sulindac 200 ppm; •, diets containing sulindac 400 ppm; $\mathrm{n}=6$ in each group.

Furthermore, early invasive SCCs (EISCC) and invasive SCCs demonstrated moderately or strongly positive for COX-2. In all cases, COX-2 expression was observed in the perinuclear region to the cytoplasma.

Inhibitory effect of sulindac on tumor development and growth. Administration of sulindac was found to have a chemopreventive action against DMBA-induced cheek pouch carcinogenesis. Although all hamsters developed SCC, the onset of carcinoma formation was delayed significantly; 8.7 weeks in the control group and 14.8 and 11.8 weeks in the $200 \mathrm{ppm}$, and $400 \mathrm{ppm}$ sulindac group, respectively. In addition, tumor growth was retarded in the groups of sulindac treatment. The body weights were similar in the $200 \mathrm{ppm}$ sulindac group or rather increased in the $400 \mathrm{ppm}$ sulindac group as compared to the control group (Table I). Mean survival time was markedly prolonged; 23.7 weeks in the control group, and 36.3 and 33.8 weeks in the 200 and 400 ppm sulindac groups, respectively (Fig. 2).

Inhibition of cell growth, $P G E_{2}$ and VEGF production in HCPC-1 cells by sulindac sulfide. Sulindac sulfide caused growth inhibition of HCPC-1 cells in a dose-dependent 


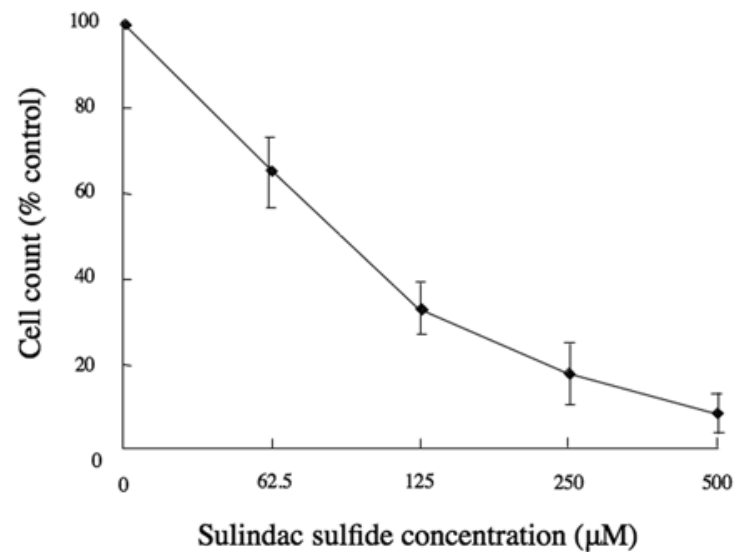

Figure 3. Cell growth inhibition in HCPC-1 cells by sulindac sulfide. Cell viability was determined by cell count after treatment of cells with various concentrations of sulindac sulfide at $37^{\circ} \mathrm{C}$ for $72 \mathrm{~h}$. Data represent the average $\pm \mathrm{SD}$ in triplicate dishes.
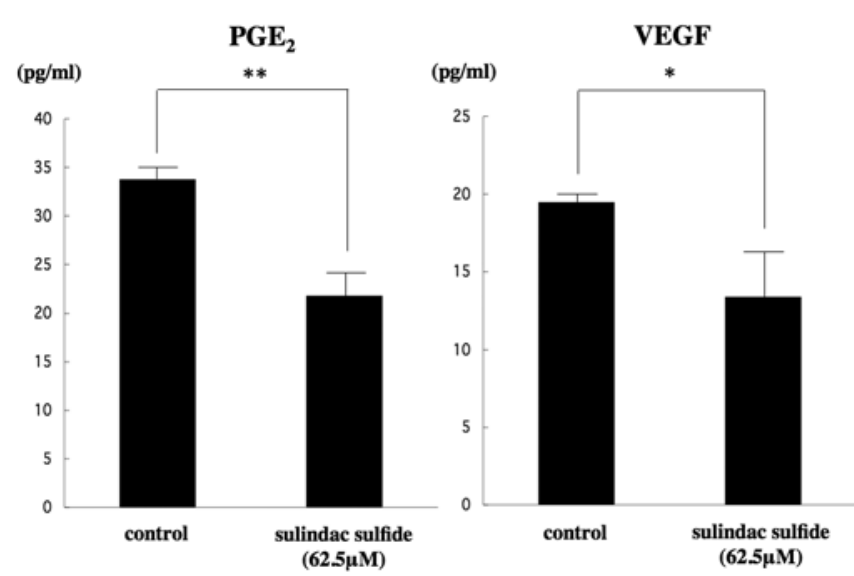

Figure 4. Effect of sulindac sulfide on $\mathrm{PGE}_{2}$ and VEGF production in HCPC-1 cells. HCPC-1 cells were plated at $5 \times 10^{4}$ cells in $3.5 \mathrm{ml}$ growth medium in $60-\mathrm{mm}$ tissue culture dishes and grown at $37^{\circ} \mathrm{C}$ for $24 \mathrm{~h}$. The $\mathrm{IC}_{30}$ concentrations of sulindac sulfide were added to the dishes and then cells were cultured for further $72 \mathrm{~h}$. The medium was discarded and $3.5 \mathrm{ml}$ of serum-free fresh medium was added to each dish, and then conditioned medium was collected after 15 min for $\mathrm{PGE}_{2}$ assay and after $24 \mathrm{~h}$ for VEGF assay. Data represent mean $\pm \mathrm{SD}$ of 3 determinations. ${ }^{*} \mathrm{P}<0.05,{ }^{* *} \mathrm{P}<0.005$.

manner (Fig. 3). Treatment with sulindac sulfide at the $\mathrm{IC}_{30}$ concentration of $62.5 \mu \mathrm{M}$ for 3 days suppressed significantly $\mathrm{PGE}_{2}$ and VEGF production by 64 and $69 \%$ of the control level in HCPC-1 cells (Fig. 4).

Decreased expression of COX-2 by sulindac sulfide. The expression of COX-2 in untreated cells was compared with that in sulindac sulfide-treated cells by Western blotting. Expression of COX-2 protein in HCPC- 1 cells by treatment with $62.5 \mu \mathrm{M}$ sulindac sulfide was decreased by 2 -fold (Fig. 5).

Inhibition of tumor angiogenesis by sulindac. When the effect of sulindac on tumor-induced angiogenesis in tumor stroma was examined histologically, the MVD was significantly lower in sulindac groups than in the control group

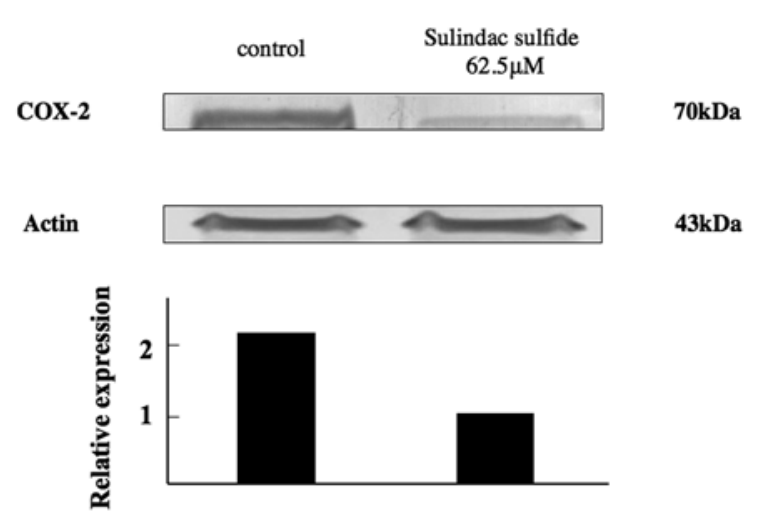

The intensity of each band

Figure 5. Western blot analysis of COX-2 protein before and after sulindac sulfide treatment in HCPC-1 cells. Expression levels of COX-2 in HCPC-1 cells were decreased by treatment $62.5 \mu \mathrm{M}$ sulindac sulfide at $37^{\circ} \mathrm{C}$ for $72 \mathrm{~h}$.

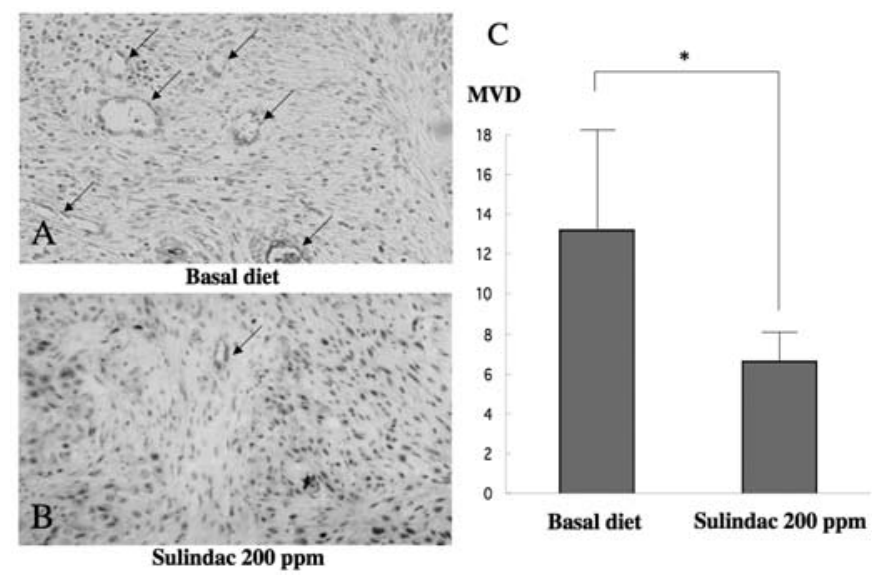

Figure 6. Microvessel formation in the stroma of DMBA-induced SCC and its inhibition by sulindac. Immunohistochemical staining for factor VIII/von Willebrand factor performed to detect microvessels in the tumor stroma of hamster cheek pouch, given (A) basal diet or (B) diets containing 200 ppm sulindac. Arrows, microvessels (original magnification, x100). (C) Microvessel density (MVD) of each group ( $n=3$ ). MVD was determined by counting the number of vessels in high-magnification field $(\mathrm{x} 400)$ of the tumor stroma that contained the highest number of capillaries. ${ }^{*} \mathrm{P}<0.05$.

given basal diet (Fig. 6). The effect was more prominent in the $200 \mathrm{ppm}$ group than in the $400 \mathrm{ppm}$ group.

\section{Discussion}

Cyclooxygenases (COXs) catalyzes the rate-limiting step in prostaglandin $(\mathrm{PG})$ biosynthesis; the conversion of arachidonic acid to the PG endoperoxides $\mathrm{PGG}_{2}$ and $\mathrm{PGH}_{2}$. They have been postulated to be target molecules for NSAIDs. Numerous experimental rodent models as well as recent epidemiological studies have shown an inverse relationship between NSAIDs intake and colon cancer development (5,6,21-23). Although the precise mechanism by which NSAIDs inhibit carcinogenesis is unclear, the available data support the hypothesis that arachidonic acid metabolism is altered through COX activity, thereby reducing eicosanoid production (24). Several experimental animal and human 
colon tumors contain high levels of PGs, which have been shown to affect cell proliferation and tumor growth and suppress immune responsiveness $(25,26)$. It is therefore reasonable to predict that inhibition of colonic mucosal or tumor PGs by specific agents may suppress the tumorigenicity of colon. The increased level of COX-2 activity may result in elevated PG levels in these lesions. COX-2 expression has also been shown to be up-regulated in human SCC of the head and neck region including oral mucosa (27). Similar findings were obtained in the rat tongue SCC model induced by 4 NQO (28). The results obtained in the present study demonstrated that increased levels of COX-2 protein are present not only in oral SCC but even in epithelial dysplasia. These data indicated that administration of sulindac produced inhibitory effects against oral SCC development both at the initiation phase and during promotion and progression phases of carcinogenesis.

Administration of NSAIDs such as aspirin and indomethacin is associated with gastrointestinal ulceration, because of their COX-1 inhibitory actions (23), and to date most studies have implicated COX-2, rather than COX-1, as an isoform involved in carcinogenesis. In the azoxymethane model of rat colon carcinogenesis, Reddy et al (23) found that $1500 \mathrm{ppm}$ celecoxib inhibits aberrant crypt foci multiplicity by $40-49 \%$ without gross changes in the intestines. We have also reported that celecoxib inhibited DMBA-induced hamster cheek pouch carcinogenesis in a dose-dependent manner (29).

In the present study, the body weights were similar or rather increased in the sulindac group as compared to the control group, indicating no side effect. In addition, there seems to be an optimal dose of sulindac to inhibit carcinogenesis, because 200 ppm of sulindac was more effective for inhibition of tumor development and growth, and survival time than $400 \mathrm{ppm}$ of sulindac. Thus, it was suggested that sulindac is a potent and non-toxic chemoprotective agent.

In recent years, the correlation between angiogenesis and development of tumor can be seen clearly in many reports, an adequate blood flow in tumor stroma was indeed essential for growth of tumors $>1-2 \mathrm{~mm}$ in size (30). It has also been assumed that transmissive, excessive aberrant new blood vessels contribute to metastasis. $\mathrm{PGE}_{2}$, which is a main product of $\mathrm{COX}-2$, promotes angiogenesis with inflammatory granulation tissue (31). Expression of angiogenesis factors such as VEGF and TGF- $\beta$ is found in colorectal cancer cell lines which overexpress $\mathrm{COX}-2$, and a production of angiogenesis factor was inhibited dose-dependently by COX-2 inhibitor (32). In intestinal polyps occurring in APC knockout mice, COX-2 is induced by interstitial cells and produced $\mathrm{PGE}_{2}$ induces VEGF via an $\mathrm{EP}_{2}$ receptor, resulting in new angiogenesis in tumor tissues (33). In this study, production of VEGF was significantly inhibited by sulindac sulfide in vitro, and the MVD was significantly decreased when animals were fed diets containing sulindac in vivo. Therefore, it was thought that angiogenic inhibition was important as one of the mechanisms of anti-tumor effect of NSAIDs.

In conclusion, our present results clearly indicated that COX-2 protein is highly expressed in dysplastic precancerous lesions and SCCs, and provided evidence that sulindac, a NSAID, possesses chemopreventive potential against DMBA-induced hamster cheek pouch carcino- genesis via anti-angiogenic action. Based on these findings, it is suggested that sulindac could serve as a potent chemopreventive agent with low toxicity against oral carcinogenesis.

\section{Acknowledgments}

This study was supported by a Grant-in-Aid for Scientific Research from Ministry of Education, Science and Culture of Japan to M.U. (No. 15390630), and Hyogo College of Medicine Research Funds.

\section{References}

1. Thun Mj: NSAID use and decreased risk of gastrointestinal cancer. Gastroenterol Clin N Am 25: 333-348, 1996.

2. Giardiello FM, Hamilton SR, Krush AJ, et al: Treatment of colonic and rectal adenomas with sulindac in familial adenomatous polyposis. N Engl J Med 328: 1313-1316, 1993.

3. Greenberg ER, Baron JA, Freeman DH Jr, et al: Reduced risk of large-bowel adenomas among aspirin user. J Natl Cancer Inst 85: 912-916, 1993.

4. Giovannucci E, Egan KM, Hunter DJ, et al: Aspirin and the risk of colorectal cancer in women. N Engl J Med 333: 609-614, 1995.

5. Dewitt DL and Smith WL: Primary structure of prostaglandin $\mathrm{G} / \mathrm{H}$ Synthase from sheep vesicular gland determined from the complementary DNA sequence. Proc Natl Acad Sci USA 85: 1412-1416, 1988.

6. Hla T and Neilson K: Human cyclooxygenase-2 cDNA. Proc Natl Acad Sci USA 89: 7384-7388, 1992.

7. O'Banion MK, Winn VD and Young DA: cDNA cloning and functional activity of a glucocorticoid-regulated inflammatory cyclooxygenase. Proc Natl Acad Sci USA 89: 4888-4892, 1992.

8. Crofford LJ, Wilder RL, Ristimaki AP, et al: Cyclooxygenase-1 and 2 expression in rheumatoid synovial tissues: effect of interleukin-1ß, phorbol ester and cortico-steroids. J Clin Invest 93: 1095-1101, 1994.

9. Rao CV, Rivenson A, Simi B, et al: Chemoprevention of colon carcinogenesis by sulindac, a non-steroidal anti-inflammatory agent. Cancer Res 55: 1464-1472, 1995.

10. Boolbol SK, Dannenberg AJ, Chadburn A, et al: Cyclooxygenase- 2 overexpression and tumor formation are blocked by sulindac in a murine model of familial polyposis. Cancer Res 56: 2556-2560, 1996.

11. Cruz-Correa M, Hylind LM, Romans KE, et al: Long-term treatment with sulindac in familial adenomatous polyposis: a prospective cohort study. Gastroenterology 122: 641-645, 2002.

12. Giardiello FM, Spannhake EW, DuBois RN, et al: Prostaglandin levels in human colorectal mucosa: effects of sulindac in patients with familial adenomatous polyposis. Dig Dis Sci 43: 311-316, 1998.

13. Giardiello FM, Casero RA Jr, Hamilton SR, et al: Prostanoids, ornithine decarboxylase, and polyamines in primary chemoprevention of familial adenomatous polyposis. Gastroenterology 126: 425-431, 2004.

14. Sawaoka H, Tsuji S, Tsuji M, et al: Cyclooxygenase inhibitors suppress angiogenesis and reduce tumor growth in vivo. Lab Invest 79: 1469-1477, 1999.

15. Skopinska-Rózewska E, Piazza GA, Sommer E, et al: Inhibition of angiogenesis by sulindac and its sulfone metabolite (FGN-1): a potential mechanism for their antineoplastic properties. Int J Tissue React 20: 85-59, 1998.

16. Urade M, Uematsu T, Mima T, et al: Serum dipeptidyl peptidase (DPP) IV activity in hamster buccal pouch carcinogenesis with 9,10-dimethyl-1,2-benz-anthracene. J Oral Pathol Med 21: $109-112,1992$.

17. Wood GD and Warnke R: Suppression of endogenous avidin binding activity in tissue and its relevance to biotin-avidin detection system. J Histochem Cytochem 29: 1196-1204, 1981.

18. Ovejera AA, Houchens DP and Baker AD: Chemotherapy of human tumor xenografts in genetically athymic mice. Ann Clin Lab Sci 8: 50-56, 1978. 
19. Odukoya O, Schwartz J, Weichselbaum R, et al: An epidermoid carcinoma cell line derived from hamster 7,12-dimethylbenz $(\alpha)$ anthracene-induced buccal pouch tumors. J Natl Cancer Inst 71: $1253-1264,1983$

20. Takaoka K, Kishimoto H, Segawa E, et al: Elevated cell migration, invasion and tumorigenicity in human $\mathrm{KB}$ carcinoma cells transfected with COX-2 cDNA. Int J Oncol 29: 1095-1101, 2006.

21. Thun MH, Namboordiri MM, Calle EE, et al: Aspirin use and reduced risk of fatal cancer. Cancer Res 53: 1322-1327, 1993.

22. Reddy BS, Rao CV, Rivenson A, et al: Inhibitory effect of aspirin on azoxymethane-induced colon carcinogenesis in F344 rats. Carcinogenesis 14: 1493-1497, 1993.

23. Reddy BS, Rao CV and Seibert K: Evaluation of cyclooxygenase-2 inhibitor for potential chemopreventive properties in colon carcinogenesis. Cancer Res 56: 4566-4569, 1996.

24. Rigas B, Goldman IS and Levine L: Altered eicosanoid levels in human colon cancer. J Lab Clin Med 122: 518-523, 1993.

25. Marnett LJ: Aspirin and the potential role of prostaglandins in colon cancer. Cancer Res 52: 5575-5589, 1992.

26. Smith WL: Prostanoid biosynthesis and mechanisms of action. Am J Physiol 263: F181-F191, 1992.
27. Chan G, Boyle JO, Yang EK, et al: Cyclooxygenase-2 expression is up-regulated in squamous cell carcinoma of the head and neck. Cancer Res 59: 991-994, 1999.

28. Shiotani S, Denda A, Yamamoto K, et al: Increased expression of cyclooxygenase-2 protein in 4-Nitroquinoline-1-oxide- induced rat tongue carcinomas and chemopreventive efficacy of a specific inhibitor, nimesulide. Cancer Res 61: 1451-1456, 2001.

29. Nishimura N, Urade M, Hashitani S, et al: Increased expression of cyclooxygenase (COX)-2 in DMBA-induced hamster cheek pouch carcinogenesis and chemopreventive effect of a selective COX-2 inhibitor celecoxib. J Oral Pathol Med 33: 614-621, 2004.

30. Zetter BR: Angiogenesis and tumor metastasis. Ann Rev Med 49: 407-424, 1998.

31. Ghosh AK, Hirasawa N, Niki H, et al: Cyclooxygenase-2mediated angiogenesis in carrageenin-induced granulation tissue in rats. J Pharmacol Exp Ther 295: 802-809, 2000.

32. Tsujii M, Kawano S, Tsuji S, et al: Cyclooxygenase regulates angiogenesis induced by colon cancer cells. Cell 93: 705-716, 1998.

33. Sonoshita M, Takaku K, Sasaki N, et al: Acceleration of intestinal polyposis through prostaglandin receptor EP2 in Apc Knockout mice. Nat Med 7: 1048-1051, 2001. 